\title{
Effectiveness of Hospital Management Committees in Busia County, Kenya
}

\author{
William N. Okedi ${ }^{*}$, Ferdinard Adungo ${ }^{2}$ \\ ${ }^{1}$ Department of Public Health and Behavioural Sciences, Alupe University College, Busia, Kenya \\ ${ }^{2}$ Kenya Medical Research Institute, Nairobi, Kenya \\ Email: *w.okedi@gmail.com, ferdinard.adungo@gmail.com
}

How to cite this paper: Okedi, W.N. and Adungo, F. (2021) Effectiveness of Hospital Management Committees in Busia County, Kenya. Health, 13, 1129-1144. https://doi.org/10.4236/health.2021.131008 4

Received: September 21, 2021

Accepted: October 24, 2021

Published: October 27, 2021

Copyright $\odot 2021$ by author(s) and Scientific Research Publishing Inc. This work is licensed under the Creative Commons Attribution International License (CC BY 4.0).

http://creativecommons.org/licenses/by/4.0/

\begin{abstract}
The Kenya Ministry of Health restructured the health sector in 2009 with the goal of promoting and improving the health status of all citizens. It established the Hospital Management Services Fund to be managed at the facility level by the Hospital Management Committees (HMCs). Since the establishment of the HMCs at the county level following the devolution of health services in 2016, no evaluation has been done to assess their performance in $\mathrm{Bu}-$ sia County. We assessed the criteria, selection process, orientation, induction, and the performance of the HMCs in Busia and considered their implications for Kenya and similar contexts in Africa. Data were collected by purposive sampling of all HMC members in six level 4 and one level 5 hospitals through Focus Group Discussions and key informant interviews. Documents collected both at the facility and county levels were analysed and used appropriately. All seven hospitals evaluated did not fully comply with the National Guidelines. Three (43\%) of the hospitals nominated persons with educational levels below the required O-level certification. Another $3(43 \%)$ contravened the Constitution of Kenya (2010) by excluding persons with disabilities and minorities. The study identified systemic commissions and omissions in the recruitment process, leading to anxiety and frustrations by members of HMCs, staff and the catchment population of the respective hospitals. In conclusion, the nominated HMC members have no legitimacy to assume their roles and responsibilities as they have not been gazetted, appointed, oriented, and facilitated.
\end{abstract}

\section{Keywords}

Health, Reform, Governance, County, Management

\section{Introduction}

The United Nations Sustainable Development Goal on health (UN SDG 3) envi- 
sions a world that is safer, fairer and healthier for everyone. To achieve this goal, access to quality essential healthcare services is paramount. Therefore, it behooves governments to develop, strengthen and implement national strategies and programmes in order to achieve the health targets by the year 2030. One such approach is Universal Health Coverage (UHC). It is based on the principle of providing access to affordable quality essential health services in a manner that promotes collective action.

The community is a major stakeholder in building and expanding equitable, resilient and sustainable health systems. Primary health care which is funded through public finance can deliver integrated, comprehensive people-centered services for all. Essential to this approach is health sector reforms and policies that will facilitate monitoring and accountability for equitable progress towards UHC. In Kenya, the engagement of communities in ensuring accountability and representation of the people's voice is achieved through the health facility management committees. Through the analysis of compliance, audits and accreditation, gaps and areas for improvement are identified and recommendations are made to ensure a high standard of health care is achieved [1].

In 2010, the people of Kenya unanimously voted against a centralized system of government in favour of a devolved system of government as enshrined in the Constitution of Kenya 2010 [2]. The main goals of devolution include among others to promote social and economic development as well as the provision of proximate, easily accessible services throughout Kenya.

Section 43, 1, (a) of the Constitution of Kenya 2010 states: "Every person has the right to the highest attainable standard of health which includes the right to health care services including reproductive health care". Delivery of Health Services is among key functions that were devolved to the 47 County Governments. This was in line with the decentralisation policies of the 1990s and in common with public health services in many other developing countries.

The main goal of the health sector is "to promote and improve the health status of all Kenyans through the deliberate restructuring of the health sector to make all health services more effective, accessible and affordable" [3]. In tandem with the political reforms in the country, the Government of Kenya (GOK) approved the Kenya Health Policy Framework [4], as a blueprint for developing and managing health services. The policy framework is aimed at responding to the declining health sector expenditure, outdated health laws, inadequate management skills at lower levels, increasing burden of diseases, and rapid population growth.

To accomplish its goal, the $\mathrm{MOH}$ initiated reforms meant to increase the level of decision-making at the facility level [3]. The reforms included: 1) Establishing the Hospital Management Services Fund (HMSF) in line with the Financial Management Act of 2009 [5] to be managed by the National Hospital Services Committee (NHSC) at the national levels and the HMC at the hospital level and 2) Replacing the Hospital Boards at the facility level with the HMCs. These reforms were expected to reduce administrative bureaucracy and enhance effec- 
tiveness of management by increasing the financial autonomy of hospitals through the increased role of the local community in the management of lower-level health facilities [3] [6]. Significant progress and success have been reported in low and middle-income countries with regard to the role of health facility management committees especially in the implementation of health policies and guidelines [7]. However, a number of limitations still exist with regard to the participation of the community in the selection, training, composition and roles of the HMCs [8]. This study set out to investigate the characteristics of the Busia County HMCs and assess the level of compliance with the various Health Acts and policies and their implications on overall performance.

\section{Background}

\subsection{The Busia Context}

In 2016, the County Government of Busia enacted the Busia County Health Services Act [9] which established the HMCs for each health facilities. Whereas the Health Act bestows the appointing authority on the Executive Member responsible for health, it spells out conditions that must be fulfilled by the appointing Authority. For instance, the HMC remains answerable to the Chief Officer for health; ensure gender balance and representation of the youth, persons with disability and marginalized groups. Section 29 of the Act outlines the responsibilities of the HMCs including liaising and cooperating with the community, the County and national agencies on issues of health services and care delivery.

\subsection{Problem Statement}

Since the inception of the Busia County Health Services Act and the establishment of the HMCs as vital governance structures in 2016, no evaluation has been done to assess the functioning of these committees. Furthermore, the members of the HMCs continue to draw allowances from the county government. Therefore, periodic evaluation of the HMCs' performance is needed as an accountability measure to the County Government of Busia and its people.

\subsection{Objectives}

The primary aim of the study was to assess the performance of the Hospital Management Committees in the affairs of their respective health facility.

The specific objectives were:

1) Review the criteria, composition, and appointment process of the members of the HMCs for the period 2019/2021.

2) Assess the Performance of the HMCs in their oversight role in the management of critical events in their respective sub-county hospitals.

\section{Materials and Methods}

\subsection{Study Design}

A cross-sectional descriptive study design was chosen because it was appropriate 
for describing the processes of selection and performance of the HMCs across the seven hospitals in Busia County.

\subsection{Study Population}

The study population included all the appointed members, chairpersons, and secretaries of the HMCs. The study also covered all the ex-officio members of the HMCs namely the respective hospital administrative officers, the sub-county administrative officers and nursing officers.

\subsection{Setting}

The study was conducted in seven government hospitals categorised as follows:

- Level 5: Busia County Referral hospital.

- Level 4: Port Victoria, Sio Port, Khunyangu, Alupe, Kocholya, and Nambale sub-county hospitals.

\subsection{Sampling Frame}

A purposive sample of all the members of the HMCs; co-opted members (nursing officer, sub-county administrators and the hospital administrative secretaries), the County Director of preventive and promotive services; the County Director of curative and rehabilitation services; the County Administrative Officer and the Chief Officer of the department of health and sanitation was involved in the study.

\subsection{Sample Size}

All recruited HMC members $(n=63)$; hospital in-charges $(n=7)$, hospital administrative officers $(n=7)$ and sub-county administrative officers $(n=7)$ were involved.

\subsection{Time Frame}

The study covered approximately Nine (9) months, commencing in May 2019 with a feedback workshop for the research participants in September 2019 and ending with a dissemination seminar for all the members of health facility committees in the county of Busia in January 2020.

\subsection{Data Collection}

A combination of approaches was used in data collection. These included: 1) Review of literature on health sector reforms and devolution of health services and documents including county integrated development plans (CIDPs) of 2013-2017

[9]; Facility record reviews and evaluation reports on performance of HMCs by other external agencies; 2) Focus Group Discussions with HMC members and 3) Key informant interviews with health professionals. Review of literature on health sector reforms in Kenya was done by retrieving and reading different published information accessible in PubMed, google scholar, and the Laws of 
Kenya databases. Information on the national health plans and policies and other relevant health services evaluation reports were analysed. Health sector reforms and policies are usually initiated through the legislative process of the republic; most information was available from secondary sources as reference documents in specific government websites and county legislation statutes.

\subsection{Data Analysis}

The National Governance Guidelines for HMCs for levels 4 and 5 [3] and the Busia County Health Services Act, 2016 [10] provided the primary analytical framework. A thematic analysis was done for qualitative data while quantitative data was summarised and presented in tables.

\section{Results and Discussion}

The results of the assessment of the performance of the HMCs according to the research objectives are presented and discussed. The participation of the HMC members from each hospital was as follows: Busia County Referral hospital (9), Port Victoria (5), Sio Port (8), Khunyangu (8), Alupe (9), Kocholya (9), and Nambale (8) giving a total of 56 against the expected 63 members. Not everyone was available at the time of the survey due to other official engagement. Some HMC members had travelled outside the county. In addition, the sub-county administrators (7), hospital administrators (7) and hospital in-charges (7) all participated in the study.

\subsection{Criteria for Membership}

The study found that all seven hospitals were not compliant with the National Governance Guidelines for HMCs as well as the requirements of the Busia Health Services Act, 2016 [10] summarised in Table 1. More specifically, it was evident that:

Table 1. Compliance with membership criteria.

\begin{tabular}{|c|c|c|c|c|c|}
\hline \multicolumn{6}{|c|}{ Membership Criteria } \\
\hline Hospital & $\begin{array}{l}\text { Number of } \\
\text { members }\end{array}$ & Years in Office & $\begin{array}{c}\text { Education } \\
\text { below O-level }\end{array}$ & Residence Outside area & Compliance \\
\hline Khunyangu & 10 & All serving 1 st term & $1 \mathrm{CPE}$ & No & No \\
\hline Nambale & 9 & All serving 1st term & 1 Form 2 & No & No \\
\hline Alupe & 9 & $\begin{array}{l}\text { One member serving } \\
2 \text { nd term, rest } 1 \text { st term }\end{array}$ & $\begin{array}{l}\text { Information } \\
\text { not provided }\end{array}$ & No & \\
\hline Busia County Referral & 12 & All serving 1 st term 1 & $\begin{array}{c}\text { Incomplete } \\
\text { information provided }\end{array}$ & $\begin{array}{l}\text { Yes, Chairman works, } \\
\text { resides in Bungoma county }\end{array}$ & No \\
\hline Kocholya & 9 & 3 serving 2 nd term, 61 st term & $1 \mathrm{KJCE}$ & No & No \\
\hline Sio Port & 10 & All serving 1 st term & Incomplete & $\begin{array}{l}\text { Yes, Chairman resides } \\
\text { in Nairobi County }\end{array}$ & No \\
\hline Port Victoria & 6 & All serving 1 st term & $\begin{array}{l}\text { Information } \\
\text { not provided }\end{array}$ & $\begin{array}{l}\text { Chairman works, } \\
\text { resides in Nairobi }\end{array}$ & No \\
\hline
\end{tabular}

Source: Chief Officers letter of $17^{\text {th }}$ May 2019 on Gazettement of HMCs for Busia. 
- Khunyangu, Busia Referral and Sio Port hospitals appointed more members into the HMCs than required.

- Khunyangu, Nambale and Kocholya engaged persons with certificates below the mandatory O level, certificate of primary education (CPE), Form 2 and Kenya junior certificate of education (KJCE) respectively.

- Educational records for all new members of the HMCs of Port Victoria and Alupe Hospitals were missing in documents held at the County level.

- Sio Port and Busia County Referral hospitals had incomplete educational records for their HMC members.

- Private health practitioners were included in the HMCs of Nambale, Khunyangu, Busia Referral, and Kocholya hospital.

- Alupe HMC did not have representation of persons with disability and minorities.

- Most members of the HMCs were residents of the county, while Chairpersons of Port Victoria and Sio Port HMCs resided in Nairobi County; and the Chairperson of Busia Referral HMC worked and resided in Bungoma County.

The implications of selecting people not meeting the requirements for example those with lower educational levels, may affect the performance of the HMCs in several ways. First during the HMCs deliberations such members may hardly comprehend the issues under discussion and therefore hardly make any useful contributions. On the other hand, chairpersons not resident in the catchment areas of the hospital are rarely available for consultation with hospital management, and rarely attend scheduled meetings due to distance and competing interests. More importantly, such members become a liability to the community and the institution that sustains their continued stay in the HMCs without value addition.

\subsection{Composition of the Hospital Committees}

The Busia Health Services Act, 2016 required that HMCs have gender balance and representation of youth, persons with disability, minorities, and marginalized groups. The findings of this study on the composition of the HMCs in $\mathrm{Bu}-$ sia County are summarised in Table 2. Overall, the HMCs comprised the persons envisaged both in the National Governance Guidelines and in the Busia Health Services Act, 2016. However, the following variations were found:

- In Khunyangu HMC, Community-based organization (CBOs) and persons with disability and minorities were not represented.

- Private Practitioners who were not included in the National Governance Guidelines were members of the HMCs of all hospitals.

- Only Khunyangu and Alupe hospitals elected their chairpersons are required.

- Nambale hospitals did not include the Sub-County medical officer in the HMC.

- In Alupe and Kocholya HMCs, persons with disability and minorities were not represented. 
Table 2. Composition of Busia county hospital management committees.

\begin{tabular}{|c|c|c|c|c|c|c|c|c|c|}
\hline \multicolumn{10}{|c|}{ Membership of HMBs } \\
\hline Hospital & $\begin{array}{l}\text { Chair } \\
\text { Selected by } \\
\text { Committee }\end{array}$ & $\begin{array}{l}\text { Facility } \\
\text { in Charge } \\
\text { Secretary }\end{array}$ & $\begin{array}{c}\text { Sub-county } \\
\text { Admin/County Director } \\
\text { of Administrator Member }\end{array}$ & $\begin{array}{l}\text { Rep. } \\
\text { Youth }\end{array}$ & $\begin{array}{c}\text { Private } \\
\text { Practitioner }\end{array}$ & $\begin{array}{l}\text { Sub-County } \\
\text { MOH }\end{array}$ & $\begin{array}{c}\text { Rep. } \\
\text { Women }\end{array}$ & $\begin{array}{l}\text { Rep } \\
\text { FBOs }\end{array}$ & $\begin{array}{l}\text { Rep. } \\
\text { CBOs }\end{array}$ \\
\hline Khunyangu & Yes & Yes & Yes & Yes & Yes & Yes & Yes & Yes & No \\
\hline Nambale & No & Yes & Yes & Yes & Yes & No & Yes & Yes & Yes \\
\hline Alupe & Yes & Yes & Yes & Yes & Yes & Yes & Yes & Yes & Yes \\
\hline $\begin{array}{c}\text { Busia County } \\
\text { Referral Hospital }\end{array}$ & No & Yes & No & Yes & Yes & Yes $^{*}$ & Yes & Yes & Yes \\
\hline Kocholya & No & Yes & Yes & Yes & Yes & Yes & Yes & Yes & Yes \\
\hline Sio Port & No & Yes & Yes & Yes & Yes & Yes & Yes & Yes & Yes \\
\hline Port Victoria & No & Yes & No & Yes & No & No & Yes & Yes & No \\
\hline
\end{tabular}

Source: Chief Officer Health letter of $17^{\text {th }}$ May 2019 on Gazettement of HMCs for Busia County.

- Busia County Referral Hospital has an expanded HMC membership which included County director of Curative services, the Chief Officer of the department of Health and sanitation, an extra woman in addition to the women representative and a community representative.

- One additional member in Sio Port HMC whose affiliation, identification details and qualifications were missing.

- Only Port Victoria hospital HMC nominated a finance expert.

- In all the hospitals covered in this study, the nursing officers' in-charge and the hospital administrative officers are co-opted members of the HMCs.

- The Busia Health Services Act was at variance with the National Governance Guidelines for HMCs [3] with regards to the inclusion of Private health practitioners and Development partners to the HMCs.

- In Kocholya hospital, the deputy county Commissioner was involved in the HMC activities on the account of his role on security and vetting of nominees. This was however, not observed in the other hospitals.

The exclusion of persons with disability and minorities in Khunyangu, Alupe and Kocholya HMCs was a violation of the Kenya Constitution 2010, on equality and freedom from discrimination. The implication of this omission is that matters affecting this specialised groups are likely not to be effectively addressed and at best receive only lip-service.

Whereas this was not the original objective of this study, it became apparent that the Busia Health Services Act which created the HMCs, in particular section 28 (1) which deals with the establishment and composition of the HMCs was at variance in some instances with the National Governance Guidelines for HMCs (analogous with Boards) for levels 4 and 5. For example, Private health practitioners and Development partners not mentioned in the National Guidelines but were included in the HMCs according to the county health services Act, 2016 [10]. The implications of such divergence in law are beyond the scope of this 
study. The study further found the Busia Health Services Act, 2016 was limited in scope (critical information and guidance) needed to facilitate effective organization and functioning of HMCs.

\subsection{Selection Process}

The Busia County Health Services Act, 2016 does not provide guidance on the process for selection of HMCs. However, the National Governance Guidelines for levels 4 and 5 hospitals describes the process [3]. The study examined the selection process for new members of HMCs using some key indicators shown in Table 3.

An analysis of the main actors in the implementation of key activities in the selection of new HMC members revealed the following:

- In all hospitals except Nambale, the initiation and coordination of the selection of new HMC members was done by the respective Medical Officer in-charge in consultation with the Chief Officer Health and Sanitation.

- In Nambale hospital, the initiation, coordination, and nomination of new HMC members was done by the sub-county administrator in consultation with opinion leaders. A final list of nominees was handed to the Medical Officer in-charge for onward delivery to the Chief Officer Health and Sanitation.

- The out-going HMCs in Kocholya and Nambale Hospitals had been notified of the expiry of their tenure and existence of vacancies for new members in their respective hospitals. No such notifications had been issued to the other out-going HMCs in the other hospitals.

- There was no evidence that specific group members for example women, youth, FBOs and persons with disability were involved in nominating their representatives to the HMCs.

Table 3. Key actors in the selection of members of hospital management committees.

\begin{tabular}{|c|c|c|c|c|c|c|}
\hline Hospital & $\begin{array}{l}\text { Initiator \& } \\
\text { Coordinator }\end{array}$ & $\begin{array}{l}\text { Notification } \\
\text { to Out-Going } \\
\text { HMC Done }\end{array}$ & $\begin{array}{l}\text { Nominators of } \\
\text { New Members }\end{array}$ & $\begin{array}{c}\text { Approval } \\
\text { of Nominees } \\
\text { Done at Sub-County }\end{array}$ & $\begin{array}{l}\text { Appointment and } \\
\text { Gazettement Done }\end{array}$ & $\begin{array}{l}\text { Hospitals } \\
\text { Informed }\end{array}$ \\
\hline Port Victoria & Medical officer In-Charge & No & MP/MCA and SC Admin & No & No & No \\
\hline Sio Port & Medical Officer In-Charge & No & MP/MCA and SC Admin & No & No & No \\
\hline Khunyangu & Medical Officer In-Charge & No & MP/MCA and SC Admin & No & No & No \\
\hline Alupe & Medical Officer In-Charge & No & MP/MCA and SC Admin & No & No & No \\
\hline Kocholya & Medical Officer In-Charge & Yes & $\begin{array}{l}\text { MP/MCA/SCC, SC Admin } \\
\text { Comm Dev. Officer, } \\
\text { Hospital In-Charge }\end{array}$ & No & No & No \\
\hline Nambale & SC Administrator & Yes & MP/MCA and SC Admin & No & No & No \\
\hline $\begin{array}{l}\text { Busia } \\
\text { County } \\
\text { Referral }\end{array}$ & Medical Superintendent & No & $\begin{array}{l}\text { HMT/Consultation } \\
\text { Other Professionals }\end{array}$ & Yes CHMT & No & \\
\hline
\end{tabular}

Source: Key Informant Interviews in study hospitals, June \& July 2019. 
As evidenced in Table 3, the main actors in the selection of new members of the HMCs in the county of Busia were the politicians namely the respective Members of Parliament (MPs) and the Members of the County Assemblies (MCAs) assisted by the Sub-County Administrators. At the county level, interviewees reported involvement of high-level political leadership in vetting the nominees especially at the County referral hospital where a nominee for the position of Chairperson of the HMC was dropped and replaced without further involvement of the hospital management team.

The nomination process for the Kocholya hospital members was however more elaborate and included the participation of the political leaders (MCA and MP); Community Development officer; Deputy County Commissioner and the Medical Officer in-charge of the hospital. The key informant ably articulated the rationale for inclusion of each of the officials in the nomination process.

- Although respondents reported to have received guidelines for selection of new members, no evidence had been provided both at the hospital level and at the Chief Officers Level to verify the assertion. The guidelines received by the hospitals dealt with the composition of members but not the details of the selection process.

- It was found that no sub-county development committees or equivalent governance structure existed across all the seven sub-counties and therefore no notification or approval was sought from them.

- The research found that in a circular dated $5^{\text {th }}$ October 2018 addressed to Medical Superintendents; health administrative officers and facility in-charges, the Chief Officer requested for copies of academic certificates, personal identification number, tax certificates and phone numbers of nominated committee members of their respective facilities.

- Through a circular dated $5^{\text {th }}$ March 2019, the Chief Officer directed the Medical officers in-charge of Hospitals to work with the new committees pending their gazettement, they were also directed to facilitate the new members to assume their roles and to inform the out-going HMCs to hand over to the new team.

- The study found that none of the new Committee members had received an appointment letter nor been Gazetted.

Overall, the study found that to a large extent, the selection process was driven by political interests. For example, in Port Victoria Hospital, the medical officer in-charge in her letter dated $9^{\text {th }}$ October 2018 forwarding required documents of nominated individuals to the Chief Officer Health, wrote:

"After subterranean consultations between the area Member of Parliament for Budalangi Constituency Hon. Raphael Biita Sauti Wanjala and the area member of the County Assembly Hon. Taabu Were, they anonymously agreed on the following individuals as nominees for the Hospital Management Committee."

The failure to involve the special interest groups such as women groups, Faith Based Organizations (FBOs), Youth and Persons with Disability in the selection of their representatives to the HMCs can be attributed to the lack of clear guide- 
lines on the selection process, inadequate supervision, and coordination of the entire selection process. The absence of a selection committee in any of the sub-counties charged with nominations and preliminary approval of nominees was a drawback to the process. The implications of these omissions are that you have a non-representative group in the HMCs whose ability and motive to improve delivery of health services to the community and allegiance to the people's aspirations is in doubt. These findings are consistent with previous studies [11] [12] which found that among the factors affecting performance of Health Facility Committees is the composition of such committees.

\subsection{Orientation and Induction of New Members}

The purpose of orientation and induction according to the National Governance Guidelines [3] is to ensure members are effective in performance of their expected roles. Three key activities are envisaged:- review of the roles, responsibilities, and expectations of the new members; dissemination of an information pack which provides a comprehensive information of the hospital including HMC structure and the hospital annual report; and an introductory visit to the hospital including introduction to the Hospital Management Team.

This study found that following the instructions of the Chief Officer Health via circular dated $5^{\text {th }}$ March 2019, all hospitals except Port Victoria, inaugurated their HMC. The handing over which was done in Khunyangu; Nambale and Kocholya was poorly attended on average by 2 - 3 members of the out-going Committee. No handing over took place in Alupe, Sio Port, Port Victoria, and Busia County referral hospital.

The new HMC members in Alupe and Khunyangu elected their chairpersons and established HMC sub-committees. The types of committees established by the Hospital Management Committees are shown in Table 4. Only three hospitals had established sub-committees and only one had an Audit committee. Most HMCs members explained that they had only attended the introductory cum

Table 4. Sub-committees of the hospital management committees.

\begin{tabular}{cccccc}
\hline & \multicolumn{5}{c}{ Committees Established } \\
\cline { 2 - 6 } Hospital & Executive/Finance & $\begin{array}{c}\text { Quality } \\
\text { Assurance }\end{array}$ & $\begin{array}{c}\text { Project } \\
\text { Development }\end{array}$ & Inspection/Acceptance & Other \\
\hline Port Victoria & No & No & No & No & No \\
Sio Port & No & No & No & No & No \\
Khunyangu & Yes & Yes & Yes & No & No \\
Alupe & No & No & No & No & No \\
Kocholya & Yes & Yes & No & No & Audit \\
Nambale & Yes & Yes & Yes & No & No \\
Busia & No & No & No & No & No \\
\hline
\end{tabular}

Source: Records and documents at participating hospitals. 
inauguration meetings and had received no follow-up communication on the next course of action.

Port Victoria HMC had not held any meeting since the selection of the committee members in October 2018 due to the uncertainty of their legal standing which was feared to attract litigation given the volatile political situation in the area. It was also found that in some hospitals not only was handing over not done in the introductory meetings, but members were asked to perform some key functions. For example, in Alupe hospital, the new committee members were asked to approve the hospital budget even without appointment, gazettement, handing over and induction. It is evident that no orientation and inductions of new HMCs was conducted in the county. This was confirmed by the senior officials at the County level but blamed lack of funds for their inability to conduct the activity. They stated that they were dependant on development partners and international NGOs working on governance issues but that they had not identified any that was willing to support the exercise. Seemingly, this is never budgeted for by the relevant department.

The implication of not orienting and inducting new committee members to their roles and functions is poor performance and bad outcomes for the health of the community. Indeed, orientation and induction can be viewed as commencement of capacity building and training of HMCs to play their roles effectively. Previous studies [13] showed that Operational issues including training adversely affected the performance of HMCs.

\subsection{Understanding of Core Functions, Roles and Responsibilities}

In general, most HMC members had a general understanding of their role as a link between the hospital and the community they serve. Majority explained that in the absence of an orientation, induction and in lack of communication from the nominating authority, they were unclear of their roles. In contrast, members who were serving their second terms in Khunyangu, Nambale and Kocholya hospitals understood and correctly articulated the functions and responsibilities of the HMCs as they reported to have been inducted in their first term.

It was not only the HMC members who were not clear of their roles and responsibilities. Most of the committee secretaries had no clarity about their roles in the committee as they were new in their work stations and had not been inducted to issues of facility management. This research also found out that the members of the HMCs were not aware of the remuneration they were to receive. The committee secretaries reported paying varying figures as shown in Table 5. Briefly, the study found that most members of the HMCs were very dissatisfied with the current remuneration they are receiving. A chairperson of one of the HMC who had served from 2009-2012 as chairperson lamented that several years since he first left the committee, he finds himself being paid the same allowance despite spiralling cost of living. The consequences of un-informed HMCs to the operations of the hospital include confusion, job dissatisfaction, 
Table 5. Remuneration of hospital management committees.

\begin{tabular}{ccc}
\hline \multirow{2}{*}{ Hospital } & \multicolumn{2}{c}{ Allowances Payable per Sitting (Ksh) } \\
\cline { 2 - 3 } & Chairman & Members \\
\hline Port Victoria & NA & NA \\
Sio Port & 4000 & 2000 \\
Khunyangu & 3500 & 2000 \\
Alupe & NA & NA \\
Nambale & 4000 & 3000 \\
Kocholya & 4500 & 3000 \\
Busia Referral & NA & NA \\
\hline
\end{tabular}

NA: Not applicable.

conflicts with the hospital management teams. These findings are consistent with results of previous research [14].

In a follow-up interview with the Chief Officer Health and sanitation, he explained that according to Salaries and Remuneration Commission (SRC), Committee chairperson were entitled to an allowance of Ksh.15,000 and members Ksh. 10,000 per sitting for levels 4 and 5 hospitals. He explained that the variances observed in the hospitals covered in this study are due to the capacity of the resources generated in those facilities.

The results in this thematic area have serious policy consequences for the County and national governments. It is not only grossly unfair for the two levels of Government to withhold information from the committee members, but also decided not to pay them what is rightly theirs.

\subsection{Performance of the Health Committees}

The In all the hospitals covered in this study, there was little being implemented. However, the newly selected HMC members were enthusiastic and eager to commence their work. They were motivated by the high expectations from their communities and health care providers to resolving the challenges affecting delivery of health services in their areas. Some of the pressing issues they are expected to address include lack of finances, insecurity, pilferage of hospital resources including drugs; poor relations between community and health workers; lack of water and human resource shortages among others in their respective facilities.

This study found that the HMCs were increasingly becoming frustrated and losing morale because almost nine months since they were informed of their selection into the committees, they had not received appointment letters and had not been Gazetted and inducted. Indeed, these HMC members questioned their legal positions as committee members. Some lamented the lack of information on their status from the Medical Officers in-charge and from the County health and sanitation department. 
In hospitals where HMCs had been formed, some individual members of the committee took upon themselves to visit hospitals in-Cognito as part of their oversight function. For example, in Khunyangu hospital, one committee member visited the hospital to assess how the staffs were handling patients. In another example, a member of the quality assurance sub-committee in Nambale hospital, visited consultation rooms, introduced herself to the staff and made observations on the interaction between the patient and service providers pointing out the short-comings to the concerned staff. The findings above have demonstrated the cumulative effect of systemic failures in the Management of the recruitment and induction of HMCs in the county resulting in non-performance of the roles, responsibilities, and functions of the committees across the hospitals. The outcome of such failures includes frustrated members, staff and the community that had expected better services.

\subsection{Relationship between Hospital Management Committees and Health System Structures}

There was little or no interactions between the HMCs with other health system structures and other external entities in most of the hospitals covered in this study. However, the Khunyangu HMC reported to have interacted with the office of the Deputy Governor resulting in the alleviation of an acute water shortage in the facility. They had also interacted with the office of the Chief Officer Health and Sanitation and resolved a major problem involving security guards who were blocking patients to enter the hospital due to unpaid wages.

Kocholya HMC on the other hand reported their interaction with the hospital contractor who was constructing an additional ward with negative outcomes as the contractor dismissed them claiming to be answerable only to the appointing Authority at county headquarters. There was no trace of any relationships between the HMCs and other critical health system structures such as the County Health Management Services Fund Board (CHMSFB), Office of the Chief Officer Health and Sanitation as well as external development partners in the health sector.

\subsection{Establishment of the Hospital Management Services Fund (HMSF)}

All the hospitals covered in this study reported that they had not established the HMSF since the advent of devolution in 2013. They said that the Facility Improvement Fund which had been supporting service delivery was abolished by the County leadership and instead initiated a system of imprests to run the facilities.

The HMCs expressed their frustrations in their inability to meaningfully engage in the execution of their mandates in the absence of funds. They particularly raised concerns for the lack of decentralisation of funds to critical departments such as health and sanitation to facilitate delivery of services. Some of the HMCs took exception with the leadership of the County Department of Finance, 
who despite being members of the HMSFB at County level, have never attended any of the meetings, but chose to send their assistants who were ill informed of the fund and talked down the other Fund members.

\section{Conclusions}

Considering that the new members of the HMCs had not assumed their roles and functions, the conclusion is limited to the first objective. Based on the results and discussions, we draw the following conclusions:

1) The newly nominated members of the HMCs were in limbo, not certain of their official and legal standing within the health system. At best, they were viewed as a necessary structure to fulfill requirements of the National and County government legislatures and at worst viewed as an illegitimate governance structure in the health system.

2) There were glaring systemic commissions and omissions in the coordination of the HMCs that have resulted in contravention of the constitution of Kenya, the Governance Guidelines issued by the national government and the Busia Health Services Act in the selection process, non-gazettement, appointment, induction, and facilitation of these committees.

3) It is not possible to assess the performance of HMCs because their nominations have not been formalised and thus they cannot assume their responsibilities and perform their expected roles.

\section{Acknowledgements}

The authors would like to acknowledge the staff members of the seven hospitals who facilitated the HMCs to attend the Focus Group Discussion. We thank the Busia County Department of Health and Sanitation for their support in providing the documents reviewed in this study. Our gratitude goes to all the members of the HMCs for their valuable contributions to this study. Finally, we thank the management of Alupe University College for their support and facilitation.

\section{Conflicts of Interest}

The authors declare no conflict of interest.

\section{References}

[1] Koumetio Kenfack, M. (2021) Administrative and Financial Management Audit in an International Hospital. Open Journal of Business and Management, 9, 136-166. https://doi.org/10.4236/ojbm.2021.91008

[2] The Constitution of Kenya (2010) Published by the National Council for Law Reporting with the Authority of the Attorney General. http://kenyalaw.org/kl/fileadmin/pdfdownloads/Constitution\%20of\%20Kenya\%20( Repealed).pdf

[3] Ministry of Health (2011) Governance Guidelines for Hospital Management Committees (Levels 4 and 5), Nairobi-Kenya. https://www.health.go.ke/

[4] Ministry of Health and WHO (1994) The Kenya Health Policy Framework (KHPF), 
Government Printer, Government of Kenya, Nairobi (1994). http://guidelines.health.go.ke/\#/category/22/47/meta

[5] Government of Kenya (2009) Government Financial Management Act, Cap 412B (Hospital Management Services) Regulations, Government of Kenya, Nairobi.

[6] Waweru, E., Opwora, A., Toda, M., Fegan, G., Edwards, T., Goodman, C., Molyneux, S. (2013) Are Health Facility Management Committees in Kenya Ready to Implement Financial Management Tasks: Findings from a Nationally Representative Survey. BMC Health Services Research, 13, Article No. 404.

https://doi.org/10.1186/1472-6963-13-404

[7] Iwami, M. and Petchey, R. (2002) A CLAS Act? Community-Based Organizations, Health Service Decentralization and Primary Care Development in Peru. Local Committees for Health Administration. Journal of Public Health Medicine, 25, 274-275. https://doi.org/10.1093/pubmed/fdg066

[8] Jacobs, B. and Price, N. (2003) Community Participation in Externally Funded Health Projects: Lessons from Cambodia. Health Policy Plan, 18, 399-410.

https://doi.org/10.1093/heapol/czg048

[9] Council of Governors (2013) Busia County Government, County Integrated Development Plan 2013-2017.

https://devolutionhub.or.ke/resource/busia-county-integrated-development-plan-2 $\underline{013-2017}$

[10] Busia County Government (2016) The Busia County Health Services Act, 2016. Busia County Gazette Supplement No. 17, Printed and Published by the Government Printer, Nairobi.

http://kenyalaw.org/kl/fileadmin/pdfdownloads/Acts/BusiaCountyHealthServicesA ct2016.pdf

[11] Goodman, C., Opwora, A., Kabare, M. and Molyneux, S. (2011) Health Facility Committees and Facility Management-Exploring the Nature and Depth of their Roles in Coast Province, Kenya. BMC Health Services Research, 11, Article No. 229. https://doi.org/10.1186/1472-6963-11-229

[12] Oyaya, C.O. and Rifkin, S.B. (2003) Health Sector Reforms in Kenya: An Examination of District Level Planning. Health Policy, 64, 113-127. https://doi.org/10.1016/S0168-8510(02)00164-1

[13] McCoy, D.C., Hall, J.A. and Ridge, M. (2012) A Systematic Review of the Literature for Evidence on Health Facility Committees in Low- and Middle-Income Countries. Health Policy and Planning, 27, 449-466. https://doi.org/10.1093/heapol/czr077

[14] Opwora, A., Kabare, M., Molyneux, S. and Goodman, C. (2010) Direct Facility Funding as a Response to User Fee Reduction: Implementation and Perceived Impact among Kenyan Health Centres and Dispensaries. Health Policy and Planning, 25, 406-418. https://doi.org/10.1093/heapol/czq009 


\section{Appendix I: List of Abbreviations}

CBO: Community-based organization

CHMSFB: County health management services fund board

CIDP: County integrated development plans

CPE: Certificate of primary education

FBO: Faith-based organization

GOK: Government of Kenya

HMSF: Hospital management services fund

KJCE: Kenya junior certificate of education

MCA: Members of the county assembly

MOH: Ministry of health

NHSC: National hospital services committee

SRC: Salaries and remuneration commission

\section{Appendix II: Ethical Considerations}

Authority to conduct this study was given through the 2018-MOU between the County Government of Busia and the Alupe University College (AUC).

\section{Appendix III: Funding}

Alupe University College provided funding for this study.

\section{Appendix IV: Authors' Contributions}

William Okedi designed the study. William Okedi and Ferdinard Adungo-data collection, analysis and writing of the manuscript. 